\title{
What are the Implications of the Use of Modafinil as a Study Drug?
}

Karen Ellis*

University of Exeter Medical School, Exeter, England

*Corresponding author: Eliss K, University of Exeter Medical School, Exeter, England, Tel: +44 1392 661000; E-mail: kle211@exeter.ac.uk

Received Date: May 8, 2018; Accepted Date: May 16, 2018; Published Date: May 23, 2018

Copyright: (02018 Ellis K. This is an open-access article distributed under the terms of the Creative Commons Attribution License, which permits unrestricted use, distribution, and reproduction in any medium, provided the original author and source are credited.

\begin{abstract}
Modafinil, a drug licensed to treat the sleeping disorder narcolepsy, is being used increasingly for cognitive enhancement amongst students. The statistics available for students taking modafinil are of limited reliability, making the extent of the use of cognitive enhancements within an academic setting difficult to assess. The majority of evidence published suggests that modafinil provides cognitive benefit to students and healthy individuals who take it. The aim of this paper is to explore the ethical issues this raises such as the safety implications of buying modafinil over the Internet, whether it is fair for students to take modafinil for cognitive enhancement and if this suggests a need for drug screening prior to examinations.
\end{abstract}

Keywords: Narcolepsy; Medication; Smart-drug; Steroids

\section{Introduction}

Since appearing on the market in 1992 for its licensed purpose as a treatment for narcolepsy, a disorder of inappropriately regulated sleep cycles, modafinil has been taken for cognitive enhancement. This is particularly prevalent among students and shift workers, where increasing attention span and alertness has a noticeable effect on performance. Modafinil affects dopamine and noradrenaline regulated pathways in the brain [1] by directly inhibiting central uptake transporters [2], however the downstream effects of this are not yet fully understood. It has been reported that one fifth of university students in England have used modafinil [3]. The possibility that such a large proportion of the student population is using modafinil to boost their performance creates the need to look at the implications of such behavior. This essay aims to air some of the ethical issues surrounding the use of the study drug including assessing the evidence base behind its effectiveness in students, the safety of purchasing modafinil for unlicensed purposes and whether there is a need for drug screening prior to exams.

\section{Methodology}

The Sahakian and Morein-Zamir [1] paper was recommended, for providing a foundation on the field of neuroethics. An article from the BMJ, Hawkes [4] inspired the area of focus of this paper. Subsequent searches of the terms 'modafinil' and 'placebo' and 'students or healthy volunteers' on the TRIP database and PubMed revealed three articles, which were considered relevant. Google scholar provided a further two articles. The articles discounted were done so, due to being ongoing clinical trials, looking at the effectiveness of modafinil in patient groups with specific medical conditions and also research that focused cognitive effects of more than one drug. Further searches on modafinil brought forth newspaper articles, which were selected based on their reliability as a resource.

\section{Discussion}

It is difficult to quantify how many students are actually taking modafinil as a 'study-drug', due to this being an off label use of the drug. As with alcohol and drug consumption, the proportion of students taking performance enhancers will vary greatly between different establishments of education. Teter et al. [5] found $8.3 \%$ of the university population sampled had used performance-enhancing drugs, and of these, less than 3\% had used modafinil. However, a clear limitation to this survey is that ten years have passed since the survey was done, during which time the prevalence is likely to have increased. Furthermore, as survey responders were only recruited from one university in America, reliability of the concluded statistics is limited due to the geographical variation in prevalence of 'smart-drug' intake. Fitzsimons and McDonald [3] found that one fifth of university students in England have taken modafinil. In the article, the number of students that responded to the survey is not reported, this and the lack of clear methodology makes it an unreliable resource. Unintentional selection bias is likely to occur in the process of survey collections, as those who have taken modafinil are more inclined to respond to the survey, due to having a more vested interest in its subject matter. A balance is struck between this selection bias, [3] and responders worrying about anonymity or consequences of reporting having taken modafinil, preventing them from answering honestly. The inability to obtain reliable statistics on this topic makes it difficult to grasp the size of the implications modafinil has on society.

\section{Effectiveness in Student Population}

In healthy, non-sleep-deprived subjects modafinil has proven to provide a benefit to cognition, notably in the areas of executive functions [2]. Whilst the retrospective nature of this systematic review does weaken this result (as acknowledged in the review), the 24 studies considered give the conclusions drawn significant reliability.

Sandberg and Bostrom [6] propose that modafinil enables a subject to better evaluate a problem before responding to it. A statistically significant improvement in target sensitivity in rapid visual 
information processing was noted for those with a lower IQ versus those with a higher IQ, having taken modafinil [7]. This could be due to those with a naturally higher IQ having a better baseline of cognitive function seen in situations such as evaluating a problem.

In contrast, Fernandez et al. [8] found that modafinil only enhances performance of non-demanding tasks, but has no amplifying effect on cognitive performance in healthy non-sleep-deprived students. Selection bias of including only health science students may have resulted in a selection of students with a higher IQ. The group taking modafinil only performed significantly better on the Stroop test, showing an increase in selective attention. It is unclear how these results specifically are taken into account, the assumption is made that the task has low cognitive contingency but this is not explained.

All the studies assessing the effect of modafinil on cognition, examine cognitive function in slightly different ways. The tests used examine one small aspect of attention or performance such as visual processing, however cognition itself is a vastly complicated combination of skills that is yet to be fully understood. Therefore, a limitation to current research, noted by all the studies, is the lack of gold standard in testing cognition and the reflection of these tests on the individual's ability to perform tasks such as learning and memorizing.

\section{Drug Screening}

There is a broad spectrum of beliefs on the fairness of cognitive enhancements for students. While some people may consider taking them cheating, or gaining an unfair advantage, others view them as an option of maximizing their potential [1]. In sport it is accepted that drug tests for doping are a necessary part of competing at a high standard. Sport ethics condemn the use of steroids and other performance enhancers, with the view that they undermine the hard work of the individual [9]. With the increasing use of 'smart-drugs' among the student population, is there a need for drug testing before exams? Whose responsibility is it to impose such a change?

\section{Post-Code Lottery}

Modafinil, like any other medication, only comes at a price. Watts [10] found that $40 \%$ of those who had taken modafinil as a cognitive enhancer had bought it online. There is no literature available that reports what students have paid for their modafinil. However, for the NHS a 28-day pack of modafinil $100 \mathrm{mg}$ tablets costs $£ 8.12$ [11]. Furthermore, it would be a logical assumption that when buying over the Internet or other sources, that the cost is the same or more than that paid by the NHS. Whilst this does not seem hugely expensive, for students that are paying thousands of pounds on tuition and living costs, it is more likely those with more money will buy modafinil. Is this any different to parents who send their children to private school for a better education? For each individual it raises the questions; how far you are willing to go and how much money are you willing to spend to improve your cognitive function.

Moreover, as with any black market, the lack of regulation breeds an environment where the buyer is at complete mercy in believing what the seller says about their product. There seems to be a difference in perception of 'study-drugs' and 'party drugs' among the student population. While the reason for taking them may be completely different, the dangers of buying ecstasy are very similar to those of buying modafinil. Is there any proof that these drugs are actually modafinil?
Without a doctor patient interaction the side effects and contraindications of a medication may not be understood or monitored. Before giving a prescription, doctors have a responsibility to ensure their patient is on no other medications that will interact and that there are no underlying health complaints that may prove dangerous whilst taking the new drug. The doctor will also ensure the patient is on an appropriate dose and course for the drug to have a positive effect. Having only been licensed in 1992 [11] and for an entirely different purpose, long-term effects of healthy individuals taking modafinil are largely unknown.

\section{Sleep Deprivation in Students}

Randall et al. [7] reported that modafinil counteracted the effect of sleep depravity in adults. Among students, especially during revision times, sleep depravity is likely to be commonplace. Stickgold [12] reports that only $11 \%$ of college students in America sleep well and $40 \%$ of students feel well rested only two days each week. Hence, modafinil is likely to give a great advantage in an exam or study situation as the students who take it are likely to be sleep deprived, where modafinil will balance out the cognitive malfunctions resulting from lack of sleep that would usually be present. Again, a small study size limits the reliability of this conclusion, with only eighty-nine participants having taken part in this study [13].

\section{Reaching Our Full Potential}

"Most of us want to reach our true potential. We might drink a cup of coffee to stay awake and alert, or go for a run, to feel on top of the job. So where's the harm in a pill" [10].

For many, taking a drug crosses an arbitrary line of what is and is not acceptable in order to achieve success. It is often overlooked that study techniques, methods of learning and counseling techniques such as cognitive behavioral therapy act as internal software which can be manipulated to enhance cognition [6]. When analyzed, this leads to the argument that cognitive function is a product of the teaching received by each individual, which is entirely based on the education provided by the teachers, schools and families of each individual. If modafinil is considered to give an unfair advantage to students, then it could be argued that further considerations should be given to factors such as caffeine intake, diet and exercise, which have a proven positive affect on attention [6].

\section{Conclusion}

Modafinil is an effective cognitive enhancer, especially among those who are sleep deprived or who have a lower IQ. It is clear that the method of assessing cognitive function effectively is an area that needs a great deal more research, as acknowledged by the majority of the studies included. Due to cognitive enhancement being an off license use for modafinil, the prevalence among student population is difficult to accurately label. The other aspects of cognitive enhancement are subjective and dependent upon personal perspective. Personally, the proportion of students taking modafinil for cognitive enhancement only affects the degree to which we should worry for student safety in obtaining substances online. Is fair to take cognitive enhancers in an academic setting such as university? My answer remains no whether there is $3 \%$ or $80 \%$ of students taking modafinil. There will always be some students who for medical or financial reasons are unable to take cognitive enhancers, therefore as all cannot take them, they should not be allowed unless prescribed for a licensed use. Examining boards and 
Citation: Ellis K (2018) What are the Implications of the Use of Modafinil as a Study Drug? Pharmaceut Reg Affairs 7: 203. doi: 10.4172/2167-7689.1000 203

Page 3 of 3

universities should consider screening for cognitive enhancers prior to academic exams, not only to encourage equality among students but also to deter them in purchasing drugs illegally.

\section{References}

1. Sahakian B, Morein-Zamir S (2011) Neuroethical issues in cognitive enhancement. J Psychopharmacol 25: 197-204.

2. Battleday R, Brem A (2015) Modafinil for cognitive neuroenhancement in healthy non-sleep-deprived subjects: A systematic review. Eur Neuropsychopharmacol 2: 1865-1881.

3. Fitzsimons S, McDonald M (2014) One in five students have used modafinil: Study drug survey results. The Tab.

4. Hawkes N (2015) Modafinil does enhance cognition, review finds. BMJ 351: 4573.

5. Teter J, McCabe S, LaGrange K, Cranford J, Boyd C (2006) Illicit use of specific prescription stimulants among college students: Prevalence, motives, and routes of administration. Pharmacotherapy 26: 1501-1510.
6. Sandberg A, Bostrom N (2006) Cognitive Enhancement: A Review of Technology.

7. Randall D, Shneerson J, File S (2005) Cognitive effects of modafinil in student volunteers may depend on IQ. Pharmacol Biochem Behav 82: 133-139.

8. Fernandez A, Mascayano F, Lips W, Painel A, Norambuena J, et al. (2015) Effects of modafinil on attention performance, short-term memory and executive function in university students: A randomized trial. Medwave 15: 6166.

9. Cahill M (2005) The ethical consequences of modafinil use. Penn Bioethics J 1: 1.

10. Watts S (2011) Do cognitive-enhancing drugs work? BBC Health.

11. NHS PrescQIPP (2015) Bulletin 113. Modafinil: Restriction on indications and evidence for off-label uses. BMJ.

12. Stickgold R (2008) Sleep and Memory. Get Sleep.

13. https://www.evidence.nhs.uk/formulary/bnf/current/4-central-nervoussystem/44-cns-stimulants-and-drugs-used-for-attention-deficithyperactivity-disorder/modafinil 